
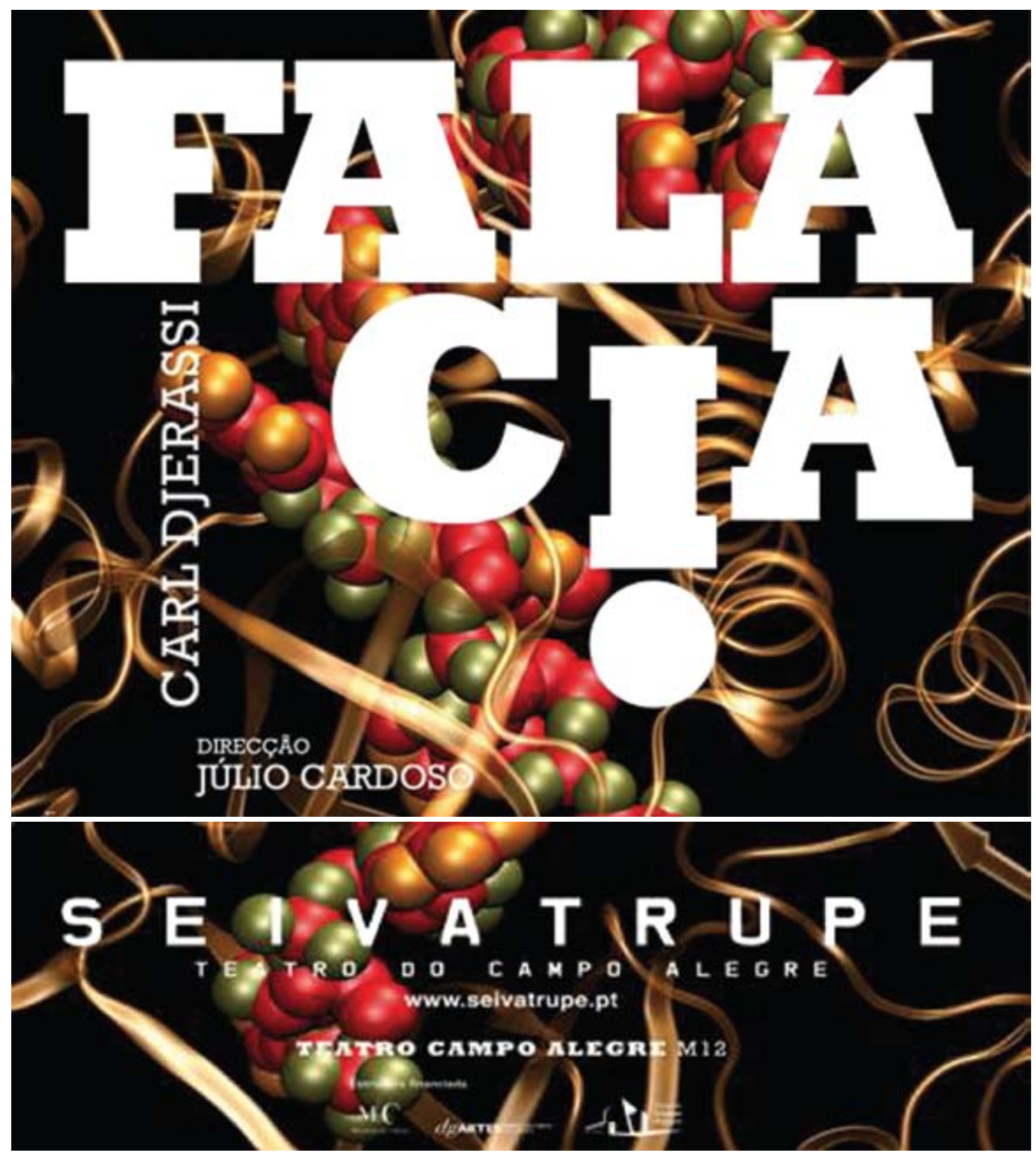

\title{
Uma Nova Tabela Periódica no Ano Internacional da Química!
}

Ao longo do ano transacto, a revista Chem 13 News dinamizou as actividades para a preparação de uma Tabela Periódica ilustrada, comemorativa do Ano Internacional da Química (AIQ).

Os docentes leitores da revista Chem 13 News puderam registar os seus alunos para desenvolverem artisticamente a interpretação de um elemento da Tabela Periódica e escreverem um pequeno texto explicativo - até 100 palavras, em inglês [1].

A tabela periódica elaborada por aquela revista teve, assim, como base as contribuições de estudantes de Química de várias províncias do Canadá, de vinte estados dos EUA e de outros catorze países. Entre estes inclui-se Portugal, representado pela Escola Secundária Infante D. Henrique, no Porto, tendo-Ihe sido atribuído o elemento químico Európio (Eu) [2].

O contributo português para a ilustração desta Tabela Periódica comemorativa do $\mathrm{AIQ}$ está representado na figura 1, podendo a consulta integral da mesma ser efectuada online [3].

A denominação do Európio, o elemento químico com número atómico 63 , advém da homenagem feita ao continente europeu, como é evidenciado no mapa incluído na representação apresentada. Além disso, sendo o Infante D. Henrique o patrono da escola portuguesa participante, a escolha para o símbolo do elemento recaiu sobre um motivo náutico, um astrolábio.

Acresce referir que as chaminés de reactores nucleares simbolizam uma das primeiras utilizações comerciais do európio - usado como absorvente de neutrões, nos reactores nucleares, para o controlo das reacções em cadeia, inerentes à fissão do urânio e do plutónio. 
Este trabalho foi desenvolvido pelos alunos da turma $C$ do $11 .^{\circ}$ ano do Curso Profissional de Técnicos de Análises Laboratoriais da Escola Secundária Infante D. Henrique do Porto (cidade indicada na figura por um marcador [2]), com o apoio dos mes-

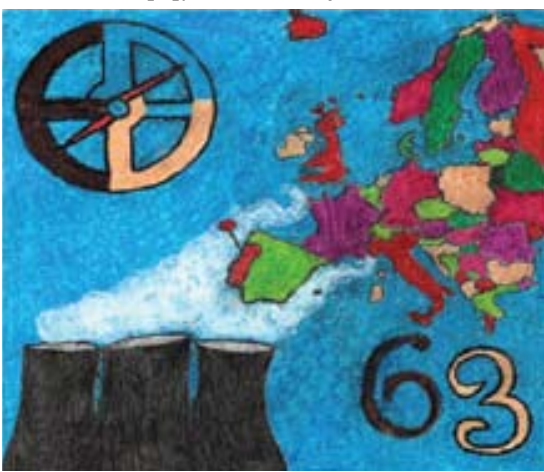

trandos da FCUP Daniel Tiago Ribeiro e Eduarda Manuela Faria, integrados no Núcleo de Estágio de Física e Química 2010/2011 desta escola, bem como o do seu orientador Fernando Pires Basto.

\section{REFERÊNCIAS}

[1] International Year of Chemistry (IYC): http://chemistry.uwaterloo. ca/iyc (Department of Chemistry of the University of Waterloo, acedido em 27-07-2011).

[2] Europium: http://chemistry.uwaterloo.ca/iyc/europium (Department of Chemistry of the University of Waterloo, acedido em 27-072011).

[3] Periodic Table Project: http:// chemistry.uwaterloo.ca/iyc/periodic-table-project (Department of Chemistry of the University of Waterloo, acedido em 27-07-2011).

Daniel Ribeiro

(danieltiago.ribeiro@gmail.com)

Membro do Núcleo de Estágio de Física e Química 2010/2011 da Escola Secundária Infante D. Henrique

Figura 1 - Ilustração do elemento Európio, pelos alunos da Escola Secundária Infante D. Henrique

\section{Size MatTers?}

A organização dos elementos químicos numa tabela, evidenciando relações entre propriedades de elementos vizinhos (na vertical, na horizontal e na diagonal), publicada por Dmitri Mendeleev em 1869, é ainda motivo de fascínio para todos os que gostam de Ciência.

A Tabela Periódica é uma das grandes conquistas intelectuais da Humanidade. Deve-se salientá-lo aos nossos alunos e estimular a sua curiosidade para compreender a organização periódica dos elementos. Uma boa maneira de o fazer é construir tabelas periódicas visualmente atractivas (por exemplo, http://periodictable.com) ou conseguir uma utilização excelente de meios audiovisuais (http://www.periodicvideos.com).

No nosso caso, seguimos a máxima size matters e propusemos à FCUL que se construísse uma tabela periódica no pátio de acesso ao edifício $\mathrm{C} 8$ (onde está instalado o Departamento de Química e Bioquímica).

Justificação dupla para a despesa: Ano Internacional da Química (http:// www.dqb.fc.ul.pt/2011AIQ/index.php) e comemoração do centenário da Faculdade (http://www.fc.ul.pt/centenario/exposicoes.php).
O local encontrado é particularmente adequado a uma (grande) tabela periódica, porque o chão é constituído por placas quadradas de betão, com $90 \mathrm{~cm}$ de lado, em número suficiente para todos os elementos. Foi aliás essa estrutura que sugeriu a ideia agora executada. Teria sido a mão de Deus que guiou o risco do arquitecto do C8 (Gonçalo Byrne) para uma solução tão adequada a uma tabela periódica?

\section{J. A. Martinho Simões (jamsimoes@ fc.ul.pt) e Fernando J. V. Santos} (fjsantos@fc.ul.pt)

Departamento de Química e Bioquímica da Faculdade de Ciências da Universidade de Lisboa

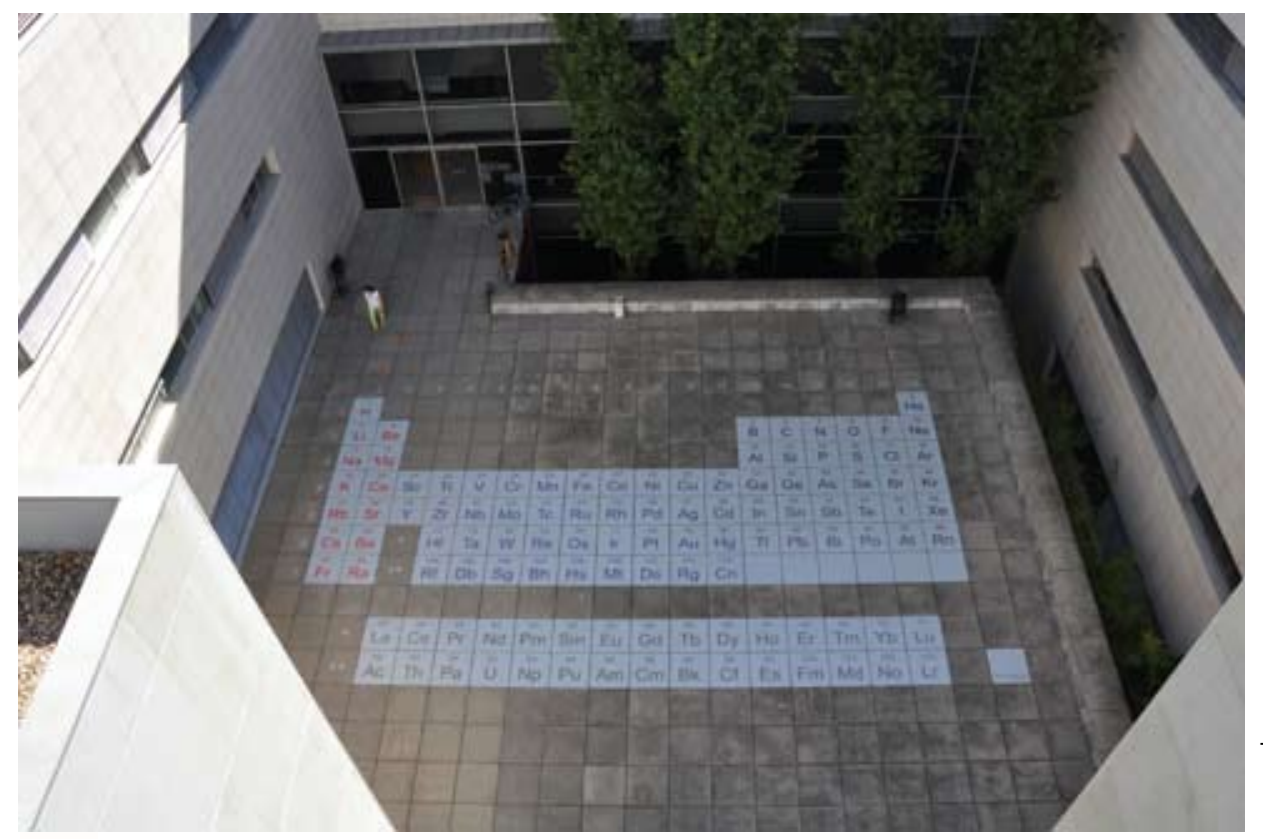

Tabela Periódica construída no pátio de acesso ao edifício C8 da Faculdade de Ciências da Universidade de Lisboa 